\title{
Effect of Strontium Carbonate Content on Flexural Strength of Clay-Based Membrane Supports
}

\author{
Jung-Hye Eom, Young-Wook Kim ${ }^{\dagger}$, and In-Hyuck Song* \\ Functional Ceramics Laboratory, Department of Materials Science and Engineering, The University of Seoul, Seoul 02504, Korea \\ *Engineering Ceramics Group, Korea Institute of Materials Science, Changwon 51508, Korea \\ (Received September 15, 2015; Revised October 12, 2015; Accepted October 13, 2015)
}

\begin{abstract}
The effect of $\mathrm{SrCO}_{3}$ content on the microstructure, porosity, flexural strength, and pore size distribution of clay-based membrane supports was investigated. Green compacts prepared from low cost materials such as kaolin, bentonite, talc, sodium borate, and strontium carbonate were sintered at $1000^{\circ} \mathrm{C}$ for $8 \mathrm{~h}$ in air. It was possible to control the porosity of the clay-based membrane supports within the range of $33 \%$ to $37 \%$ by adjusting the $\mathrm{SrCO}_{3}$ content. The flexural strength of the clay-based membrane supports was found to strongly depend on their porosity. In turn, the porosity was affected by the $\mathrm{SrCO}_{3}$ content. The average pore size and flexural strength of the clay-based membrane supports containing $4 \mathrm{wt} \% \mathrm{SrCO}_{3}$ were $0.62 \mu \mathrm{m}$ and $33 \mathrm{MPa}$ at $34 \%$ porosity.
\end{abstract}

Key words : Membranes, Clay, Strontium carbonate, Porosity, Strength

\section{Introduction}

$\mathbf{R}$ ecently, ceramic membranes have attracted increasing interest in filtration applications because of their excellent chemical and thermal stability, high mechanical strength, and resistance to harsh chemical conditions; these materials also show high separation efficiency compared to that of polymeric membranes. ${ }^{1-7)}$ Membrane supports are known as a key part of asymmetric ceramic membranes, providing mechanical strength and flow transport for the top coatings of membranes. ${ }^{8)}$ Most ceramic membranes have been prepared from alumina $\left(\mathrm{Al}_{2} \mathrm{O}_{3}\right)$, titania $\left(\mathrm{TiO}_{2}\right)$, zirconia $\left(\mathrm{ZrO}_{2}\right)$, and silica $\left(\mathrm{SiO}_{2}\right)$. Many studies on the performance of such membranes or their composites have been carried out. $^{9-12)}$ However, the application of ceramic membranes has been limited by the high cost of both the materials and the sintering process. To overcome these drawbacks, some researchers have focused on the development of low-cost ceramic membranes, such as zeolite membranes ${ }^{13)}$ and natural mineral-based membranes. ${ }^{3,14-16)}$

Previous works on low cost ceramic membranes can be summarized as follows. Mohammadi et al. ${ }^{17)}$ prepared a tubular kaolin membrane with a pore size of a few micrometers for oil-water emulsion separation and investigated the effects of the operating conditions on the membrane performance. Sahnoun and Baklouti ${ }^{18)}$ prepared flat ceramic membrane supports from kaolin, phosphoric acid, and starch mixtures

${ }^{\dagger}$ Corresponding author: Young-Wook Kim

E-mail : ywkim@uos.ac.kr

Tel : +82-2-6490-2407 Fax : +82-2-6490-2404 and investigated the effects of phosphoric acid content, sintering temperature, and compaction pressure on the permeability and mechanical properties of the membranes. Ghouil et $a l .{ }^{19)}$ processed tubular kaolin supports with pore sizes ranging from 0.4 to $20 \mu \mathrm{m}$ for microfiltration applications. Belibi et $a l{ }^{20)}$ fabricated low cost ceramic membrane supports using Cameroonian clay and characterized the low cost ceramic membranes for microfiltration applications to produce clean water. Eom et $a l .^{21)}$ fabricated low-cost membrane supports using kaolin and sodium borate; the prepared ceramic membranes offered a flexural strength of $19 \mathrm{MPa}$ at $37 \%$ porosity. Vasanth et al. ${ }^{3)}$ fabricated low-cost ceramic membrane supports using kaolin, quartz, and calcium carbonate as raw materials by uniaxial dry compaction. The prepared supports offered good flexural strengths (28-34 MPa) ${ }^{3,21)}$ and moderate pore sizes $(0.2-1.3 \mu \mathrm{m}) .^{3,19,21)}$ The obtained results suggest that low-cost ceramic membranes made of natural minerals have high potential for the purification and exploitation of waste waters.

A previous work ${ }^{22)}$ on clay-based membrane supports made from kaolin, bentonite, talc, sodium borate, and alkaline-earth oxide in carbonate forms $\left(\mathrm{MgCO}_{3}, \mathrm{CaCO}_{3}\right.$, and $\mathrm{SrCO}_{3}$ ) investigated the effect of additive composition on the flexural strength of clay-based membrane supports. With $1 \mathrm{wt} \%$ addition of alkaline-earth oxide to carbonate forms, the flexural strength of the membrane supports increased from $29 \mathrm{MPa}$ to $43-53 \mathrm{MPa}^{22}$ In the present study, the effects of $\mathrm{SrCO}_{3}$ content on porosity, pore size, and flexural strength were investigated. $\mathrm{SrCO}_{3}$ acted as a pore former as well as a pore size adjusting agent in the membranes. The incorporation of $\mathrm{SrO}$ additive in an 
intergranular phase may provide a new opportunity for improving the mechanical properties of clay-based membrane supports.

\section{Experimental Procedure}

Kaolin $\left(\mathrm{Al}_{2} \mathrm{O}_{3} \cdot 2 \mathrm{SiO}_{2} \cdot 2 \mathrm{H}_{2} \mathrm{O}\right.$, extra pure, Samchun Pure Chemical Co. Ltd., Pyeongtaek, Korea), bentonite (Yakuri Pure Chemicals Co. Ltd., Kyoto, Japan), talc (3MgO 4$\mathrm{SiO}_{2} \cdot \mathrm{H}_{2} \mathrm{O}$, Samchun Pure Chemical Co. Ltd., Pyeongtaek, Korea), sodium borate $\left(\mathrm{Na}_{2} \mathrm{~B}_{4} \mathrm{O}_{7} \cdot 10 \mathrm{H}_{2} \mathrm{O}\right.$, Samchun Pure Chemical Co., Ltd., Pyeongtaek, Korea), and strontium carbonate $\left(\mathrm{SrCO}_{3}\right.$, Daejung Chemicals and Metals Co. Ltd., Siheung, Korea) were used as starting materials. Kaolin and bentonite are low-cost clay minerals and talc is a lowcost silicate mineral. Sodium borate was added to increase the flexural strength of the membranes. In contrast, $\mathrm{SrCO}_{3}$ was used as a pore forming agent as well as a pore size adjusting agent. Five batches of powder mixtures were prepared with varying $\mathrm{SrCO}_{3}$ contents: 0, 2, 4, 8, and $16 \mathrm{wt} \%$ (see Table 1). All batches were milled separately in a polypropylene jar for $24 \mathrm{~h}$ using distilled water and $\mathrm{Al}_{2} \mathrm{O}_{3}$ grinding balls. Polyethylene glycol was added as an organic binder. The milled slurry was dried at $100^{\circ} \mathrm{C}$ for $24 \mathrm{~h}$ and uniaxially pressed under a pressure of $50 \mathrm{MPa}$. The compacts were sintered at $1000^{\circ} \mathrm{C}$ for $8 \mathrm{~h}$ in air.

X-ray diffraction (XRD, D8 Discover, Bruker AXS GmbH, Germany) was conducted on the ground powders using CuKa radiation. The bulk density of the clay-based membrane supports was calculated from the weight-to-volume ratio of the samples. The total porosity of the clay-based membrane supports was measured using the Archimedes method. The open porosity and pore size distribution were measured using mercury porosimetry (AutoPore IV 9500, Micromeritics, Norcross, GA, USA). Fracture surface morphology was observed using scanning electron microscopy (SEM, S4300, Hitachi Ltd., Hitachi, Japan). For flexural strength measurements, bar-shaped samples were cut to a size of $3 \mathrm{~mm} \times 4 \mathrm{~mm} \times 30 \mathrm{~mm}$ and bending tests were performed at a constant crosshead speed of $0.5 \mathrm{~mm} / \mathrm{min}$ using a three-point bending fixture with a span of $20 \mathrm{~mm}$.

\section{Results and Discussion}

XRD analysis was carried out to identify the phases present in the SR0, SR4, and SR16 samples. Fig. 1 shows the

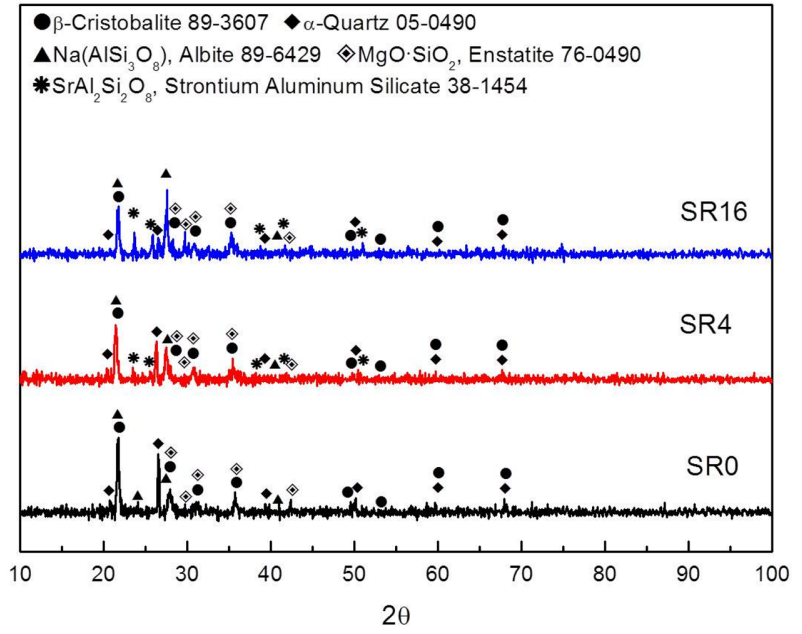

Fig. 1. XRD patterns of clay-based membrane supports sintered at $1000^{\circ} \mathrm{C}$ for $8 \mathrm{~h}$ in air.

XRD patterns of the ceramic membrane supports sintered at $1000^{\circ} \mathrm{C}$. The SR0 sample consisted of B-cristobalite, aquartz, enstatite, and albite. The SR4 and SR16 samples consisted of B-cristobalite, a-quartz, enstatite, albite, and strontium aluminum silicate. The XRD data for the SR4 and SR16 samples clearly show the formation of strontium aluminum silicate. The strontium aluminum silicate phase increased with increasing $\mathrm{SrCO}_{3}$ content in the initial composition. This indicates that the reaction between clay minerals (kaolin and bentonite) and strontium carbonate $\left(\mathrm{SrCO}_{3}\right)$ promotes the formation of strontium aluminum silicate $\left(\mathrm{SrAl}_{2} \mathrm{Si}_{2} \mathrm{O}_{8}\right)$ during sintering at $1000^{\circ} \mathrm{C}$ for $8 \mathrm{~h}$.

Figure 2 shows the bulk density and porosity of the claybased membrane supports as a function of the $\mathrm{SrCO}_{3}$ content in the starting composition. The increase in $\mathrm{SrCO}_{3}$ content in the ceramic membrane supports increased the bulk density when $\mathrm{SrCO}_{3}$ content was $2 \mathrm{wt} \%$; beyond this content, the bulk density decreased. The porosity of the claybased membrane supports decreased from $33.9 \%$ to $32.7 \%$ with an increase in the $\mathrm{SrCO}_{3}$ content from 0 wt\% to $2 \mathrm{wt} \%$, then increased continuously up to $36.6 \%$ with increasing of the $\mathrm{SrCO}_{3}$ content up to $16 \mathrm{wt} \%$. The addition of $2 \mathrm{wt} \%$ $\mathrm{SrCO}_{3}$, which transforms to $\mathrm{SrO}$ during heating, decreased the porosity from $33.9 \%$ (SR0) to $32.7 \%$ (SR2). Alkaline earth metal oxides generally react with $\mathrm{Al}_{2} \mathrm{O}_{3}-\mathrm{SiO}_{2}$, which are a major component of clay and silicate minerals, and form a liquid phase at relatively low temperatures. The

Table 1. Sample Designation and Batch Composition of Clay-based Membrane Supports

\begin{tabular}{cccccc}
\hline Sample & \multicolumn{5}{c}{ Composition (wt\%) } \\
\cline { 2 - 6 } Designation & Kaolin & Bentonite & Talc & Sodium Borate & SrCO $_{3}$ \\
\hline SR0 & 38 & 30 & 30 & 2 & 0 \\
SR2 & 37.2 & 29.4 & 29.4 & 2 & 2 \\
SR4 & 36.4 & 28.8 & 28.8 & 2 & 4 \\
SR8 & 34.8 & 27.6 & 25.1 & 2 & 16 \\
SR16 & 31.8 & 25.1 & & & 2 \\
\hline
\end{tabular}






Fig. 2. Density and porosity of clay-based membrane supports sintered at $1000^{\circ} \mathrm{C}$ for $8 \mathrm{~h}$ in air.

eutectic temperature of the $\mathrm{SrO}-\mathrm{SiO}_{2}$ system is $1358^{\circ} \mathrm{C}{ }^{23)}$ When $\mathrm{Al}_{2} \mathrm{O}_{3}$ exists, $\mathrm{SrO}-\mathrm{Al}_{2} \mathrm{O}_{3}-\mathrm{SiO}_{2}$ can form a eutectic liquid at a temperature lower than $1358^{\circ} \mathrm{C}$. Since the melting temperature of sodium borate is $742^{\circ} \mathrm{C},{ }^{24)}$ the liquid formation temperature in the present specimens, which contained sodium borate as well as $\mathrm{SrO}-\mathrm{Al}_{2} \mathrm{O}_{3}-\mathrm{SiO}_{2}$, should be lower than $1000^{\circ} \mathrm{C}$. The formed liquid phase can act as a bonding phase between the clay mineral derived grains and the partially filled residual pores; this results in a decrease of the porosity. The increase in porosity from $33.6 \%$ to $36.6 \%$ with the $\mathrm{SrCO}_{3}$ content increase from $2 \%$ to $16 \%$ was due to the volatilization of $\mathrm{CO}_{2}$, which originated from the decomposition of $\mathrm{SrCO}_{3}$ during the sintering process. This suggests that controlling the $\mathrm{SrCO}_{3}$ content in the range of $2-16 \mathrm{wt} \%$ is an efficient way to adjust the porosity of clay-based membrane supports in the range of 32.7-36.6\%. A similar tendency was also observed in porous ceramics fabricated from kaolin, bentonite, talc, sodium borate, and $\mathrm{BaCO}_{3}{ }^{25)}$
The effect of $\mathrm{SrCO}_{3}$ content on the microstructure of claybased membrane supports is shown in Fig. 3. The microstructures consisted of clay-mineral derived grains, sodium borate-strontium oxide-derived bonding phase, and residual pores. The liquid phase, formed by the reaction between sodium borate and $\mathrm{SrCO}_{3}$, acted as glue to bind the clay mineral-derived grains together. The pore morphology was mostly irregular and open pores were well distributed in the ceramic membrane supports. Fig. 4 shows the pore structures of the clay-based membrane supports at a higher magnification. Mostly transgranular fractures were observed in all specimens, indicating the strong bonding between the clay mineral derived grains formed in all specimens. Relatively smaller pores were observed in all specimens; these pores originated from the inter-particle pores in the green compact, whereas relatively larger pores, which were derived from both the agglomeration of $\mathrm{SrCO}_{3}$ and the volatilization of $\mathrm{CO}_{2}$, were observed in the SR8 and SR16 specimens. Fig. 5 shows the effect of $\mathrm{SrCO}_{3}$ content on the pore size distribution of the SR0, SR4, and SR16 specimens. The results show a unimodal pore size distribution for all specimens. The average pore diameter increased from $0.59 \mathrm{\mu m}$ to $0.99 \mu \mathrm{m}$ with an increase of the $\mathrm{SrCO}_{3}$ content. The increase in pore size with the increase in the $\mathrm{SrCO}_{3}$ content was due to the great opportunity for contact between $\mathrm{SrCO}_{3}$ particles in the compact. This type of increase in pore size with an increase in pore forming agent content has been frequently observed in many other porous ceramics. ${ }^{25-30)}$

The flexural strength of clay-based membrane supports with different $\mathrm{SrCO}_{3}$ content is shown in Fig. 6. In general, the flexural strength trend was opposite to that of the porosity (Fig. 2), and ranged from 25.9 $\mathrm{MPa}$ to $36.3 \mathrm{MPa}$. The flexural strength of clay-based membrane supports showed
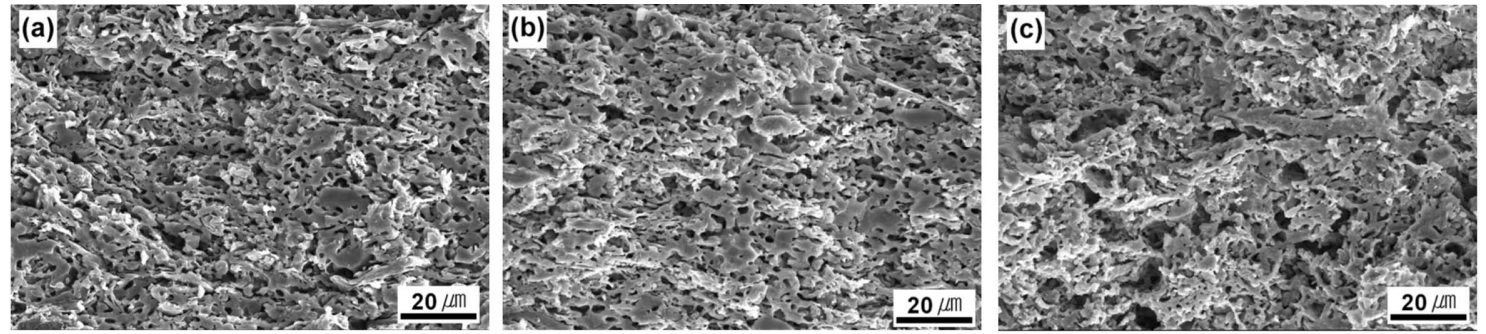

Fig. 3. Typical fracture surfaces of clay-based membrane supports sintered at $1000^{\circ} \mathrm{C}$ for $8 \mathrm{~h}$ in air: (a) SR0, (b) SR4, and (c) SR16 (refer to Table 1).
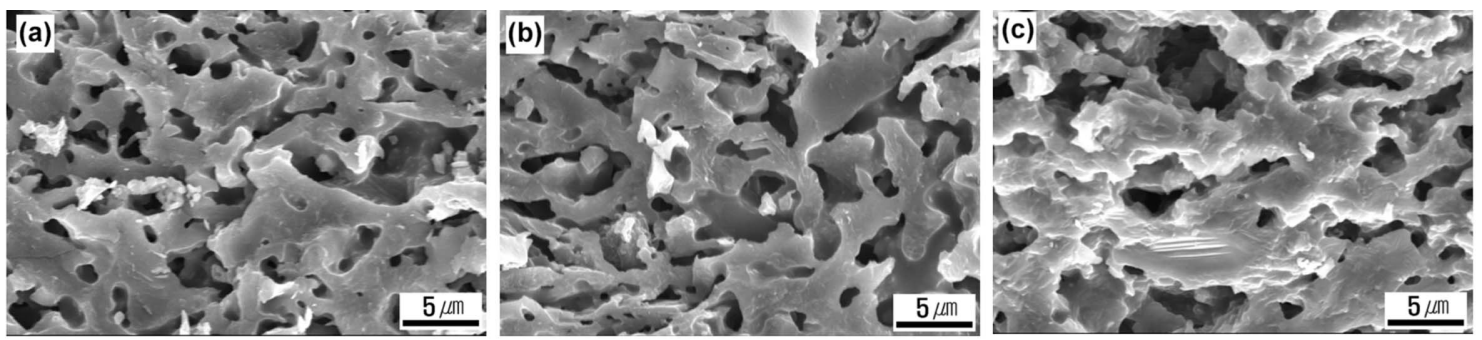

Fig. 4. Pore structures of clay-based membrane supports sintered at $1000^{\circ} \mathrm{C}$ for $8 \mathrm{~h}$ in air: (a) SR0, (b) SR4, and (c) SR16 (refer to Table 1). 

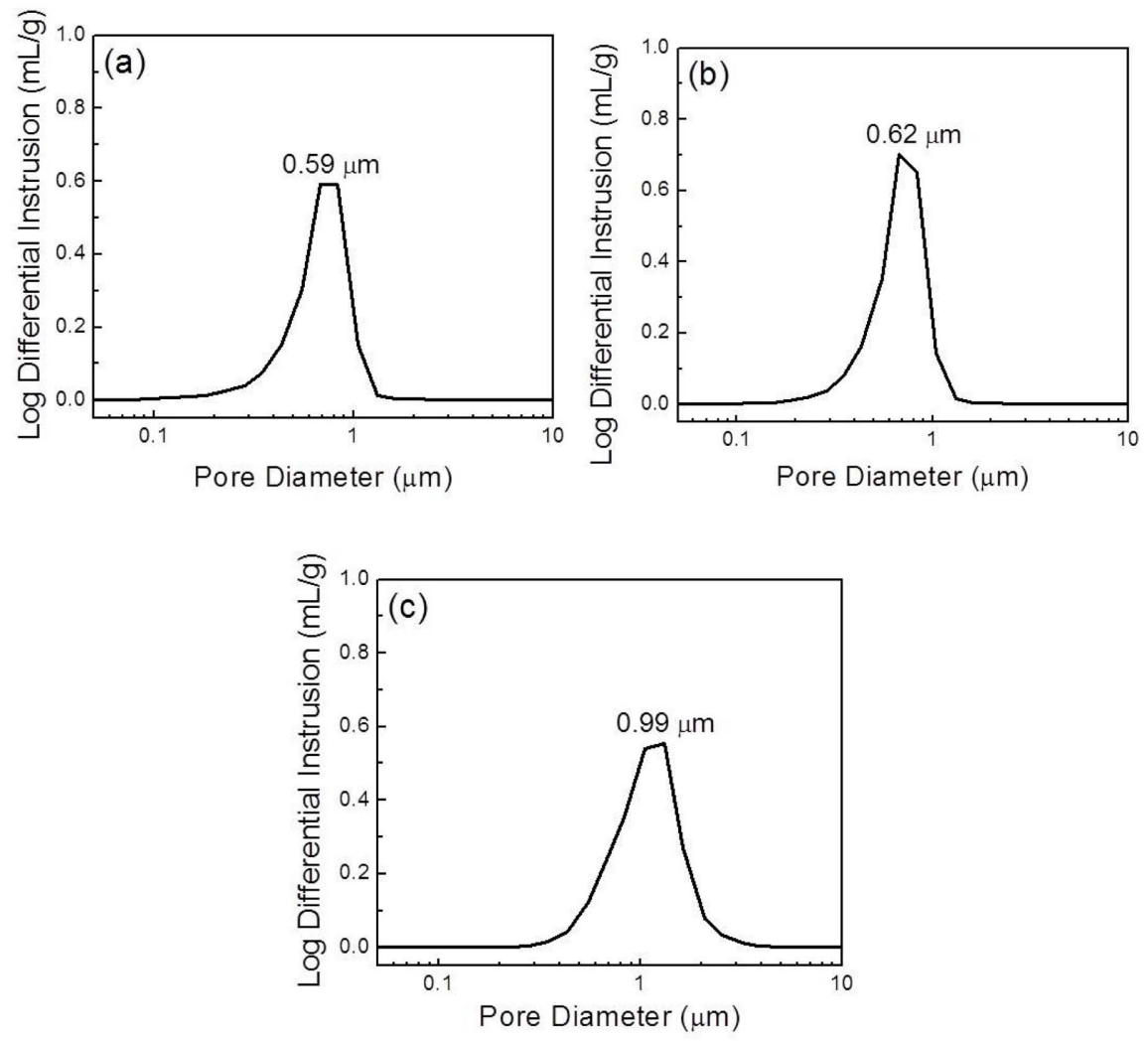

Fig. 5. Pore size distribution of clay-based membrane supports sintered at $1000^{\circ} \mathrm{C}$ for $8 \mathrm{hr}$ in air: (a) SR0, (b) SR4, and (c) SR 16 (refer to Table 1).

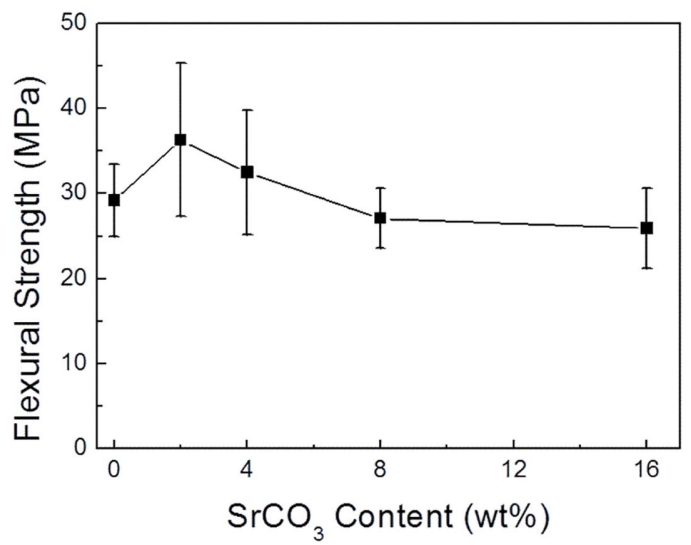

Fig. 6. Flexural strength of clay-based membrane supports as a function of $\mathrm{SrCO}_{3}$ content.

a maximum $\left(36.3 \mathrm{MPa}\right.$ ) when $2 \mathrm{wt} \% \mathrm{SrCO}_{3}$ was added. The flexural strength of the membrane supports decreased gradually to $25.9 \mathrm{MPa}$ with increasing of the $\mathrm{SrCO}_{3}$ content from $2 \mathrm{wt} \%$ to $16 \mathrm{wt} \%$. A small amount of $\mathrm{SrCO}_{3}$ addition (2 wt\%) promoted the densification of the membrane supports and decreased the porosity, resulting in the maximum strength. The large pores observed in the SR4, SR8, and SR16 specimens (Fig. 3) were attributed to the direct contact of $\mathrm{SrCO}_{3}$ particles in the green compacts and decomposition of $\mathrm{SrCO}_{3}$ during sintering. Thus, the greater amount of $\mathrm{SrCO}_{3}$ addi-

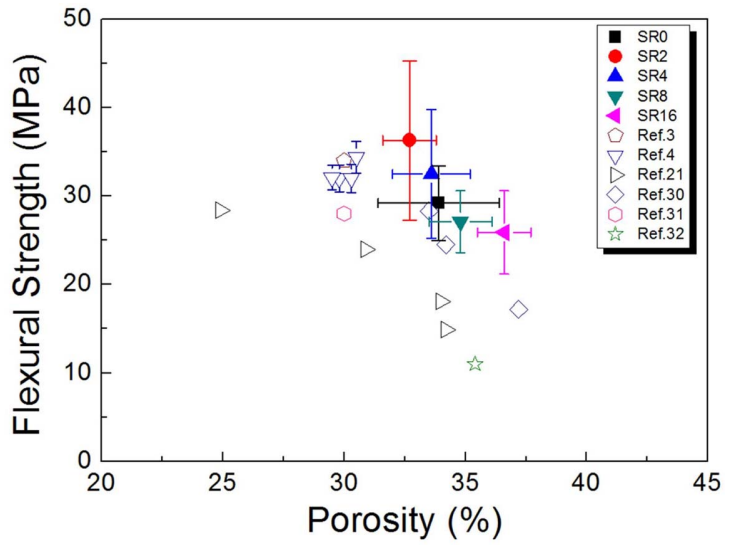

Fig. 7. Flexural strength of clay-based membrane supports as a function of porosity.

tion ( $\geq 4 \mathrm{wt} \%$ ) led to the formation of large pores, resulting in a decrease of the flexural strength. The flexural strengths of the present membrane supports were compared with the data reported in the literature for low cost ceramic membrane supports (Fig. 7). As can be seen, the typical flexural strengths of clay-based membrane supports have been reported to be 18-34 $\mathrm{MPa}$, depending on the composition and the processing conditions. Specifically, values were: 18 $\mathrm{MPa}$ at $34 \%$ porosity when the membrane supports were prepared using kaolin and sodium borate ${ }^{21)} ; 28 \mathrm{MP}$ at $34 \%$ 
porosity when the membrane supports were prepared using kaolin, bentonite, talc, and sodium borate ${ }^{30)} ; 34 \mathrm{MPa}$ at $30 \%$ porosity when the membranes were prepared using kaolin, quartz, and calcium carbonate $^{3)} ; 28 \mathrm{MPa}$ at $30 \%$ porosity $^{31)}$ and $11 \mathrm{MPa}$ at $35.4 \%$ porosity ${ }^{32)}$ when the membranes were prepared using kaolin, quartz, calcium carbonate, sodium carbonate, boric acid, and sodium metasilicate; and $34 \mathrm{MPa}$ at $30.5 \%$ porosity when the membrane supports were prepared using a Spanish clay mixture, calcite, and potato starch. ${ }^{4)}$ In contrast, typical flexural strengths of the SR2 and SR4 specimens were $36.3 \mathrm{MPa}$ at $32.7 \%$ porosity and $32.5 \mathrm{MPa}$ at $33.6 \%$ porosity, respectively. Fig. 7 clearly shows that the present strength data obtained for the claybased membrane supports with $\mathrm{SrCO}_{3}$ are superior to the other data obtained from the clay-based membrane supports sintered with other additives. The present results suggest that simultaneous addition of sodium borate and strontium carbonate is beneficial in strengthening the claybased membrane supports. The flexural strength values obtained in the present study can be considered sufficiently good so as to allow the elaborated supports to be applied in membrane operations.

\section{Conclusions}

Clay-based membrane supports with a pore size of 0.59$0.99 \mu \mathrm{m}$ have been successfully prepared by a simple uniaxial pressing route using inexpensive raw materials such as kaolin, bentonite, talc, sodium borate, and strontium carbonate. In the clay-based membrane supports, the porosity was minimized and the flexural strength was maximized when $2 \mathrm{wt} \% \mathrm{SrCO}_{3}$ was added; these ideal conditions were due to the formation of a strong bonding phase between the clay mineral derived grains. Further addition of $\mathrm{SrCO}_{3}$ from 2 wt $\%$ to 16 wt\% increased the porosity from 33 to $37 \%$, owing to the volatilization of $\mathrm{CO}_{2}$ as a result of $\mathrm{SrCO}_{3}$ decomposition during sintering. The prepared membrane supports showed good flexural strength in the range of 26$36 \mathrm{MPa}$, depending on the porosity. The average pore size and flexural strength of the clay-based membrane supports sintered with 4 wt $\% \mathrm{SrCO}_{3}$ were $0.62 \mu \mathrm{m}$ and $33 \mathrm{MPa}$ at $34 \%$ porosity.

\section{Acknowledgments}

This study was supported financially by the Fundamental Research Program of the Korea Institute of Materials Science (KIMS).

\section{REFERENCES}

1. D. S. Bae, D. S. Cheong, K. S. Han, and S. H. Choi, "Fabrication and Microstructure of $\mathrm{Al}_{2} \mathrm{O}_{3}-\mathrm{TiO}_{2}$ Composite Membranes with Ultrafine Pores," Ceram. Int., 24 25-30 (1998).

2. T. B. Kim, S. Y. Choi, and G. D. Kim, "Characterization of Ceramic Composite-Membranes Prepared by TEOS-PEG
Coating Sol (in Korean), J. Korean Ceram. Soc., 42 [3] 16570 (2005).

3. D. Vasanth, G. Pugazhenti, and R. Uppaluri, "Fabrication and Properties of Low Cost Ceramic Microfiltration Membranes for Separation of Oil and Bacteria from its Solution," J. Membr. Sci., 379 [1-2] 154-63 (2011).

4. M.-M. Lorente-Ayza, S. Mestre, M. Menendez, and E. Sanchez, "Comparison of Extruded and Pressed Low Cost Ceramic Supports for Microfiltration Membranes," J. Eur. Ceram. Soc., 35 3681-91 (2015).

5. I. H. Wi, D. W. Shin, K. S. Han, J. H. Kim, W. S. Cho, and K. T. Hwang, "Fabrication of Boehmite-based UF Ceramic Membrane (in Korean)," J. Korean Ceram. Soc., 51 [4] 337 43 (2014).

6. B. S. Bae, J. H. Ha, and I. H. Song, "Characterization and Microstructure of an Extruded Flat-Tubular-Type Alumina Filter (in Korean)," J. Korean Ceram. Soc., 51 [5] 406-12 (2014).

7. D. Song and M. Jung, "Gas Permeation of $\mathrm{Y}_{2} \mathrm{O}_{3}$-SiC Composite Membrane," J. Korean Ceram. Soc., 52 [4] 234-36 (2015).

8. I. H. Wi, D. W. Shin, K. S. Han, J. H. Kim, W. S. Cho, and K. T. Hwang, "Characteristics of the Non-electric Water Purification System Using Onggi Filter (in Korean)," J. Korean Ceram. Soc., 51 [4] 332-36 (2014).

9. Y. H. Wang, X. Q. Liu, and G. Y. Meng, "Dispersion and Stability of 8 mol.\% Yttria Stabilized Zirconia Suspensions for Dip-Coating Filtration Membranes," Ceram. Int., 33 1025-31 (2007).

10. K. A. Defriend, M. R. Wiesner, and A. R. Barron, "Alumina and Aluminate Ultrafiltration Membranes Derived Alumina Nanoparticles," J. Membr. Sci., 224 [1-2] 11-28 (2003).

11. G. T. Kim and S. H. Hyun, "Preparation and Characterization of $\mathrm{TiO}_{2}$ Ultrafiltration Membranes for Reclamation of Waste Lubricating Oil (in Korean)," J. Korean Ceram. Soc., 36 [3] 244-54 (1999).

12. S. Kroll, L. Treccani, K. Rezwan, and G. Grathwohl, "Development and Characterization of Functionalized Ceramic Microtubes for Bacteria Filtration," J. Membr. Sci., 365 [1-2] 447-55 (2010).

13. J. Cui, X. Zhang, H. Liu, S. Liu, and K. L. Yeung, "Preparation and Application of Zeolite/Ceramic Microfiltration Membranes for Treatment of Oil Contaminated Water," $J$. Membr. Sci., 325 [1] 420-26 (2008).

14. M. R. Weir, E. Rutinduka, C. Detellier, C. Y. Feng, Q. Wang, T. Matsuura, and R. L. V. Mao, "Fabrication, Characterization and Preliminary Testing of All-Inorganic Ultrafiltration Membranes Composed Entirely of a Naturally Occurring Sepiolite Clay Mineral," J. Membr. Sci., 182 [1-2] 41-50 (2001).

15. S. Khemakhem, A. Larbot, and R. B. Amar, "Study of Performances of Ceramic Microfiltration Membrane from Tunisian Clay Applied to Cuttlefish Effluents Treatment," Desalination, 200 [1-3] 307-9 (2006).

16. N. Saffaj, M. Persin, S. A. Younsi, A. Albizane, M. Cretin, and A. Larbot, "Elaboration and Characterization of Microfiltration and Ultrafiltration Membranes Deposited on Raw Support Prepared from Natural Moroccan Clay: Applica- 
tion to Filtration of Solution Containing Dyes and Salts," Appl. Clay Sci., 31 [1-2] 110-19 (2006).

17. T. Mohammadi, A. Pak, M. Karbassian, and M. Golshan, "Effect of Operating Conditions on Microfiltration of an Oil-Water Emulsion by a Kaolin Membrane," Desalination, 168 201-5 (2004).

18. R. D. Sahnoun and S. Baklouti, "Characterization of Flat Ceramic Membrane Supports Prepared with Kaolin-Phosphoric Acid-Starch," Appl. Clay Sci., 83-84 399-404 (2013).

19. B. Ghouil, A. Harabi, F. Bouzerara, B. Boudaira, A. Guechi, M. M. Demir, and A. Figoli, "Development and Characterization of Tubular Composite Ceramic Membranes using Natural Alumino-Silicates for Microfiltration Applications," Mater. Charact., 103 18-27 (2015).

20. P. B. Belibi, M. M. G. Nguemtchouin, M. Rivallin, J. N. Nsami, S. Sieliechi, S. Cerneaux, M. B. Vgassoum, and M. Cretin, "Microfiltration Ceramic Membranes from Local Cameroonian Clay Applicable to Water Treatment," Ceram. Int., 41 2752-59 (2015).

21. J. H. Eom, Y.-W. Kim, and I. H. Song, "Processing of Kaolin-Based Microfiltration Membranes," J. Korean Ceram. Soc., 50 [5] 341-47 (2013).

22. Y. I. Lee, J. H. Eom, Y.-W. Kim, and I. H. Song, "Effect of Alkaline-Earth Oxide Additives on Flexural Strength of Clay-Based Membrane Supports," J. Korean Ceram. Soc., 52 [3] 180-85 (2015).

23. J. M. Field, P. S. Dear, and J. J. Brown, "Phase Equilibria in the System BaO-SrO-SiO 2 ," J. Am. Ceram. Soc., 55 [12] 585-88 (1972).

24. K. Y. Lim, Y.-W. Kim, and I. H. Song, "Porous Sodium Borate-Bonded SiC Ceramics," Ceram. Int., 39 6827-34
(2013).

25. J.-H. Eom, Y.-W. Kim, S.-H. Yoon, and I. H. Song, "LowCost Clay-Based Membranes for Oily Wastewater Treatment," J. Ceram. Soc. Jpn., 122, 788-94 (2014).

26. J.-H. Eom, Y.-W. Kim, I. H. Song, and H. D. Kim, "Processing and Properties of Polysiloxane-Derived Porous Silicon Carbide Ceramics using Hollow Microspheres as Templates," J. Eur. Ceram. Soc., 28 1029-35 (2008).

27. B. V. M. Kumar and Y.-W. Kim, "Processing of Polysiloxane-Derived Porous Ceramics: A Review." Sci. Technol. Adv. Mater., 11044303 (2010).

28. J.-H. Eom, Y.-W. Kim, and S. Raju, "Processing and Properties of Macroporous Silicon Carbide Ceramics: A Review," J. Asian Ceram. Soc., 1 220-42 (2013).

29. I.-H. Song, I.-M. Kwon, H. D. Kim, and Y.-W. Kim, "Processing of Mirocellular Silicon Carbide Ceramics with a Duplex Pore Structure," J. Eur. Ceram. Soc., 30 2671-76 (2010).

30. Y. I. Lee, J. H. Eom, Y.-W. Kim, and I. H. Song, "Effect of Clay-Mineral Composition on Flexural Strength of ClayBased Membranes," J. Korean Ceram. Soc., 51 [5] 380-85 (2014).

31. D. Vasanth, R. Uppaluri, and G. Pugazhenthi, "Influence of Sintering Temperature on the Properties of Porous Ceramic Supports Prepared by Uniaxial Dry Compaction Method Using Low-Cost Raw Materials for Membrane Applications," Sep. Sci. Technol., 46 1241-49 (2011).

32. S. Emani, R. Uppaluri, and M. K. Purkait, "Preparation and Characterization of Low Cost Ceramic Membranes for Mosambi Juice Clarification,” Desalination, 317 32-40 (2013). 